\title{
Effect of Organic Matter on Swell and Undrained Shear Strength of Treated Soils
}

\section{Samuel Jonah Abbey ${ }^{1,}$, Adegoke Omotayo Olubanwo ${ }^{2}$, Samson Ngambi $^{2}$, Eyo Umo Eyo ${ }^{2}$, Blessing Oluwaseun Adeleke ${ }^{3}$}

${ }^{1}$ Civil Engineering Cluster, Department of Geography and Environmental Management, Faculty of Engineering and Technology, University of the West of England, Bristol, United Kingdom

${ }^{2}$ School of Energy, Construction and Environment, Faculty of Engineering, Environment and Computing, Coventry University, Coventry, United Kingdom

${ }^{3}$ Department of Civil Engineering, Faculty of Engineering, Technology and Science, University of South Wales, Cardiff, United Kingdom

Email address:

samuel.abbey@uwe.ac.uk (S. J. Abbey), aa7878@coventry.ac.uk (A. O. Olubanwo), blessing.adeleke@southwales.ac.uk (B. O. Adeleke)

${ }^{*}$ Corresponding author

\section{To cite this article:}

Samuel Jonah Abbey, Adegoke Omotayo Olubanwo, Samson Ngambi, Eyo Umo Eyo, Blessing Oluwaseun Adeleke. Effect of Organic Matter on Swell and Undrained Shear Strength of Treated Soils. Journal of Civil, Construction and Environmental Engineering. Vol. 4, No. 2, 2019, pp. 48-58. doi: 10.11648/j.jccee.20190402.12

Received: May 31, 2019; Accepted: July 1, 2019; Published: July 12, 2019

\begin{abstract}
This paper presents a laboratory and statistical study on swell and undrained shear strength of cemented organic clays blended with eco-friendly (by-product) cementitious materials such as ground granulated blast slag (GGBS) and cement kiln dust (CKD). The presence of organic matter in soils can be very problematic especially during construction of infrastructures such as roads and foundations. Therefore, experimental and statistical investigations are crucial to further understand the effect of organic matter on swell and strength performance of soils treated with by-product materials (GGBS and CKD). Five artificially synthesised organic clays with $0 \%, 5 \%, 10 \%, 15 \%$ and $20 \%$ organic matters were mixed with $20 \%$ cement during the first phase of mixing. In the second phase, cement content was reduced to $4 \%$ and blended with $12 \%$ GGBS and $4 \%$ CKD respectively. All mixed samples were cured up to 56days and subjected to undrained triaxial test and onedimensional oedometer swell test. The undrained shear strength of the untreated soils decreases from $22.47 \mathrm{kPa}$ to $15.6 \mathrm{kPa}$ upon increase in organic matter from $0-20 \%$. While the swell increases from $1.17 \%$ to $3.83 \%$ for the same range of $0-20 \%$ organic matter. The results also show improvement on strength and swell upon addition of $20 \%$ cement for all investigated samples. For samples treated with $4 \%$ cement and inclusion of $12 \%$ GGBS and $4 \%$ CKD, the treated soils showed better performance in terms of swell potential due to reduction in plasticity compared to the plasticity of soils treated with $20 \%$ cement. Undrained shear strength increases from $632 \mathrm{kPa}$ to $804.9 \mathrm{kPa}$ and from $549.8 \mathrm{kPa}$ to $724.4 \mathrm{kPa}$ with reduction in organic matter upon addition of 20\% CEM and 4\% CEM: $12 \%$ GGBS: $4 \%$ CKD after 56days. The results obtained show that the inclusion of GGBS and CKD reduced swell and increases undrained shear strength irrespective of the percentage of organic materials due to cementation effect. However, results of the statistical studies show that the presence of organic matter influences the extent of performance of the cement, GGBS and CKD treated soils.
\end{abstract}

Keywords: Stabilised Soils, Expansive Soils, Organic Matter, Undrained Strength, Swell Capacity, GGBS, Cement, CKD

\section{Introduction}

Peat is an organic material and soils rich in organic matter constitute serious challenge to vital geotechnical and geological land development undertakings especially in areas where their deposits are abundant and unavoidable. Organic clays are particularly not suitable as bedrock or foundation for structures such as roads, railways, tunnels, buildings etc., because of their potentially low bearing strength, high plasticity, high compressibility, low hydraulic and high shrinkage quality [1]. Soil mechanics practitioners and researchers have considered the study of the influence of the 
organic matter content in clays as very pertinent not only because of their undesirable mechanical and geotechnical properties but also because the amount and composition of organic matter does vary greatly in natural deposits [2, 3]. The variation of the soil properties are thought to be indirectly proportional to the organic matter content, and a minimum quantity of about $3-4 \%$ of organic matter is sufficient enough to cause a change in the soil properties [3]. Conversely, the behaviour of the clay has also been reasoned to be dependent on the nature of the organic matter [4]. Organic matter found in soils could loosely be divided into three groups: non-humic (vegetal, animal, or micro-organism remains), humic (alkanes, fatty acids, humic acids, fulvic acids, and humins) and anthropogenic contaminants (oils and a variety of compounds) $[4,5]$.

Chemical stabilization of organic clays has been adopted over the past few decades to remedy the weak engineering behaviour of organic clays. Moreover, studies on the influence of the composition of binders, curing conditions and methods of testing on major engineering properties such as the unconfined compression strength and one-dimensional compression behaviour of the stabilized product are rife $[4$, 6-15]. Only varying degrees of successes have been achieved in the utilization of calcium-based hydraulic binders such as lime and cement in the stabilization process [16]. Some studies have indicated that indeed the cementation process does occur with a formation of strong bonds between the binders and the organic clays leading to better mechanical behaviour despite the presence of organic contaminants in the stabilized product [17-19]. Notwithstanding, several studies have shown that organic matter does negatively affects the chemically stabilized soil considering that the lime or cement grains are coated by the organics (mostly humic acids) thus delaying or preventing the formation of products of hydration reaction, and therefore reducing the strength of the stabilized clays $[4,20,21]$. In fact, it has been previously reported that, even a little over $1 \%$ humic acid content present in clay could render the process of lime stabilisation ineffective $[8,12,22]$. The mechanisms of lime- treated organic clay are believed to be influenced by the moisture content and the insufficient dissolution of the clay minerals during pozzolanic reaction. Organic matters possess high water retention capacity hence limiting the quantity of water available for the hydration process [7, 23]. Furthermore, high water content may produce more spacing between aggregates, thus reducing the required cementation bonding process.

There are also concerns regarding the possibility of leaching of calcium-based binders from organic clays after stabilization [12]. Hydrogeologists have shown that water soluble organic carbon (WSOC) frequently transports contaminants through the clay soil profile and into the groundwater [24]. Therefore, WSOC may leach calcium ions from the binder used over the course of time and render the binders ineffective.

In view of the forgoing, it is suggested that some of the problems that occur in the chemical stabilization of soils of high organic matter can be avoided either by adopting a partial or total replacement of the hydraulic binders with industrial waste or by-product materials. Apart from potentially aiding the enhancement of the engineering properties of the organic clays, the introduction of wastes or by-product material guarantees a reduction in the cost of construction as well as preservation of the environment. This recommendation is in line with the current growing trend towards the use of alternative binders in soil stabilization [13, 14, 25-37].

The inclusion of Cement, PFA, and GGBS in treatment of clayey soils, reduces the plasticity index of the treated soil [30]. However, this index property can be influenced by the presence of organic matter in the clay and can affect strength. Undoubtedly, the effect of calcium-based stabilizers on geotechnical properties of soils have been studied extensively however, there seems to be little or lack of research on the stabilization of organic clays by partially replacing cement with ground granulated blast furnace slag (GGBS) and cement kiln dust (CKD). This paper will explore the possible organic clay-binder interactions and the influence of the organic matter on the strength and swelling capacity of the stabilized products. In order to achieve this, predetermined quantities of the Irish Moss Peat mixed with the clay shall be utilized to simulate the organic matter (by mass of dry clay) present in the clay. The resulting synthesized products will then be stabilized with predetermined cement quantities and subsequently replacing some of the cement quantities by GGBS and CKD in different combinations. The following objectives are set in order to implement the aim of this study:

i. Investigation of the effect of organic matter on swell and undrained shear strength.

ii. Study the performance of cement and the inclusion of GGBS and CKD in enhancing swell and undrained shear strength of the investigated soils.

iii. Statistical investigation of the significance of curing time, percentage of organic matter and binder type on the swell and undrained shear strength of the investigated soils. It is worth mentioning that percentage of organic matter as used in this study, referred to the percentage of Irish moss peat by weight of dry clay mixed with

\section{Materials and Methods}

\subsection{Materials and Sample Preparation}

The materials used in this study consisted of Clay (Soil 1), Irish Moss Peat, Portland cement, (CEM), GGBS and CKD. Irish moss peat is a fibrous and opened structured soil with high water holding capacity and a $\mathrm{pH}$ of 5.5-6, mainly used for reinvigorating garden soils, and GGBS is a cement substitute and a by-product of the production of iron. CKD is produced in high volumes during the process of cement manufacturing and are mostly used in landfills. GGBS and CKD are both by-product materials, and every year in the UK $2 \mathrm{Mt}$ of GGBS is used in the cement industry. Essentially, GGBS comprises of silicates and alumina silicates of calcium 
and other bases that are manufactured in a blast furnace under molten conditions simultaneously with the iron. There are many advantages of using GGBS and CKD in soil mixing especially the economic benefits [30]. Therefore, studying the possibility of using Cement, and inclusion of GGBS and CKD in soil mixing instead of landfilling is worthwhile because as long as cement is manufactured it would be produced. In this study, $0 \%, 5 \%, 10 \%, 15 \%$ and $20 \%$ contents of organic matter (Irish Moss Peat) by weight of dry clay were thoroughly mixed with clay for a period of $10 \mathrm{~min}$. The simulated clay-organic matter mixed soils are referred to as Soil 1, Soil 2, Soil 3, Soil 4 and Soil 5 as presented in Table 1. Thereafter, soil-mixing operation was carried out following the procedure outlined in EurosoilStab [38] for cementation of soils.

Table 1. Physical properties of the soil samples.

\begin{tabular}{lllll}
\hline Soil Property & Soil 1 & Soil 2 & Soil 3 & Soil 4 \\
\hline \% of organic matter & 0 & 5 & 10 & 15 \\
Moisture content (\%) & 24.80 & 25.47 & 26.35 & 20 \\
Liquid limit $w_{\mathrm{L}}(\%)$ & 42.5 & 41.90 & 42.75 & 31.42 \\
Plastic limit $\mathrm{w}_{\mathrm{P}}(\%)$ & 31.23 & 24.40 & 24.42 & 46.01 \\
Plasticity index & 11.27 & 17.50 & 18.33 & 26.14 \\
Plasticity ratio $(\mathrm{R}=\mathrm{LL} / \mathrm{PI})$ & 3.77 & 2.39 & 2.33 & 19.87 \\
Dry Density $\left(\mathrm{kg} / \mathrm{m}^{3}\right)$ & 1643.21 & 1562.32 & 1500.10 & 2.32 \\
\hline
\end{tabular}

In order to investigate the effect of organic matter on strength and swell properties of the treated soils, the different soil types were mixed with CEM and combination of CEM,
GGBS and CKD. Table 2 and 3 show the chemical compositions of CEM, GGBS and CKD, and the main constituents of the CEM used.

Table 2. Chemical composition of used Cement, GGBS and CKD.

\begin{tabular}{|c|c|c|c|c|c|c|c|c|c|c|c|c|}
\hline \multirow{2}{*}{ Binder Used } & \multicolumn{12}{|c|}{ Percentage of Oxides (\%) } \\
\hline & $\mathrm{SiO}_{2}$ & $\mathrm{TiO}_{2}$ & $\mathrm{Al}_{2} \mathrm{O}_{3}$ & $\mathrm{Fe}_{2} \mathrm{O}_{3}$ & MnO & MgO & Cao & $\mathrm{Na}_{2} \mathrm{O}$ & $\mathbf{K}_{2} \mathrm{O}$ & $\mathbf{P}_{2} \mathbf{O}_{5}$ & $\mathrm{SO}_{3}$ & LOI \\
\hline CEM (PC) & 20.00 & - & 6.00 & 3.00 & 0.09 & 4.21 & 63.0 & - & - & 0.20 & 2.30 & 0.88 \\
\hline GGBS & 33.28 & 0.57 & 13.12 & 0.32 & 0.316 & 7.74 & 37.16 & 0.33 & 0.474 & 0.009 & 2.21 & 442 \\
\hline CKD & 15.30 & - & 2.10 & 1.70 & - & 0.90 & 43.00 & 0.72 & 6.00 & 3.76 & 5.91 & 8.5 \\
\hline
\end{tabular}

Table 3. The main constituents of PC.

\begin{tabular}{llll}
\hline Compound name & Oxide composition & Abbreviation & \% weight \\
\hline Tricalcium aluminate & $3 \mathrm{CaO} . \mathrm{Al}_{2} \mathrm{O}_{3}$ & $\mathrm{C}_{3} \mathrm{~A}$ & 6.48 \\
Tricalcium silicate & $3 \mathrm{CaO} . \mathrm{SiO}_{2}$ & $\mathrm{C}_{3} \mathrm{~S}$ & 70.58 \\
Dicalciums silicate & $2 \mathrm{CaO} . \mathrm{SiO}_{2}$ & $\mathrm{C}_{2} \mathrm{~S}$ & 6.09 \\
Tetracalcium alumina-ferrite & $4 \mathrm{CaO} . \mathrm{Al}_{2} \mathrm{O}_{3} \cdot \mathrm{Fe}_{2} \mathrm{SO}_{3}$ & $\mathrm{C}_{4} \mathrm{AF}$ & 6.45 \\
\hline
\end{tabular}

In the first stage of mixing, the five different soil types were mixed with $20 \%$ cement content by weight of dry soil at optimum moisture content. Samples for strength test were placed into a $40 \mathrm{~mm}$ diameter by $76 \mathrm{~mm}$ height cylindrical tubes in stages and in each stage; the cylinder was tapped several times against a hard surface in order to ensure removal of any air bubble trapped within the samples. To ensure that equal degree of compaction at saturation was achieved for all mixed samples, a dead weight of $10 \mathrm{~kg}$ was placed on the mixed samples in the cylindrical tubes before extraction. Samples for the swelling test were prepared by extracting core samples of $75 \mathrm{~mm}$ in diameter and $20 \mathrm{~mm}$ height from compacted treated soils in a proctor mould. According to Ganjian et. al and Jalull et. al [39, 40], the production of cement accounts for approximately $8 \%$ of global $\mathrm{CO}_{2}$ emissions, and that cement can be substituted in a cement mix using GGBS up to 55\%. Therefore, in order to explore the economic and environmental benefits of GGBS and CKD in soil mixing, the second stage of mixing considered $80 \%$ reduction in cement and substitution of $60 \%$ GGBS and 20\% CKD leading to the production of cemented soils consisting of a blend of $4 \%$ Cem, $12 \%$ GGBS and $4 \%$ CKD. All treated samples were sealed, wrapped with a thick plastic and cured under water for 7, 14, 28 and 56 days.

\subsection{Laboratory Testing}

After proper mixing, Atterberg limit test was conducted on the treated organic clay soils to obtain the plasticity index of the soils based on procedures outlined in BS 1377-2: 1990.

Unconfined and 1-D Oedometer Compression Test

In most experimental programs reported in the literature, unconfined compression and Oedometer tests have been widely used to study undrained shear strength and expansion of swells because it is simple and fast and at the same time reliable and cheap. The indirect methods of evaluation of swell prediction are based mainly on soil properties of the soil tested and on the classification systems, meanwhile the direct methods rely on the physical estimation of the swelling potentials assessment using mainly the 1-D oedometer compression tests in the laboratory [41]. Therefore, in order to investigate the performance of cement and the inclusion of GGBS and CKD in enhancing swell and undrained shear strength of the investigated soils, both the treated and untreated samples were subjected to series of unconfined compression and swell test following the procedure outlined in BS1377-7: 1990 and BS1377-6: 1990 respectively. 
Samples were tested for strength after each curing period and the undrained shear strength was worked out as half of the average unconfined compressive strength of three samples. While samples subjected to one-dimensional oedometer compression test under $5 \mathrm{kPa}$ load were tested after 7 days.

\subsection{Statistical Validation of Investigated Factors}

A Two-way analysis of variance (ANOVA) was conducted as a means of investigating the significance of the effects of organic matter, curing time and binder combination on swell and undrained shear strength. An ANOVA two-way factor without replication was performed on undrained shear strength and swell assuming that the data are approximately normal and group may have different means but the same standard deviation. The variance was estimated and Fstatistics and p-value were adopted for significance tests. Considering an $I X J$ analysis of variance in a two-way design system, defined in terms of two independent factors (namely curing time and percentage of organic matter), applied in the prediction of a response variable, undrained shear strength $(\mu)$. An $I X J$ Matrix of Analysis of Variance (ANOVA) in a two-way design can be defined, where $I$ and $J$ represent the levels of the curing time and the percentage of organic matter respectively. In this analysis, it was considered that every level of the curing time $(I)$ appears in combination with every level of the percentage of organic matter $(J)$ resulting to a $5 \mathrm{X} 4$ Matrix and enabling the comparison of $I X J$ groups as show in Table 4.

Table 4. Levels of I and $J$.

\begin{tabular}{lllll}
\hline Level & $\mathbf{I}_{\mathbf{i}}$ & & & \\
\hline $\mathbf{J}_{\mathbf{i}}$ & $\mathbf{i}=\mathbf{1}$ & $\mathbf{2}$ & $\mathbf{3}$ & $\mathbf{4}$ \\
\hline$i=1$ & $\mu_{11}$ & $\mu_{12}$ & $\mu_{13}$ & $\mu_{14}$ \\
2 & $\mu_{21}$ & $\mu_{22}$ & $\mu_{23}$ & $\mu_{24}$ \\
3 & $\mu_{31}$ & $\mu_{32}$ & $\mu_{33}$ & $\mu_{34}$ \\
4 & $\mu_{41}$ & $\mu_{42}$ & $\mu_{43}$ & $\mu_{44}$ \\
5 & $\mu_{51}$ & $\mu_{52}$ & $\mu_{53}$ & $\mu_{54}$ \\
\hline
\end{tabular}

Where the sample size of level $i$ of the curing time and level $\mathrm{j}$ of the percentage of organic matter is equal to $\mathrm{n}_{i j}$ and the total number of observations is given as;

$$
N=\sum n_{i j}
$$

Assuming independent simple random samples (SRSs) of size $\mathrm{n}_{\mathrm{ij}}$ from each $I X J$ group with different means $\overline{\mathrm{U}}_{\mathrm{ij}}$ but equal standard deviation $\sigma$, where $\overline{\mathrm{U}}_{\mathrm{ij}}$ and $\sigma$ are unknown parameters and

let $X_{i j k}=$ the kth observation from the group having curing time at level $i$ and percentage of organic matter at level $\mathrm{j}$, then the statistical model can be written as;

$$
X_{i j k}=\overline{\mathrm{U}}_{i j}+\varepsilon_{i j k}
$$

Such that $i=1, \ldots, I$ and $j=1, \ldots, J$ and $\mathrm{k}=1, \ldots, n_{i j}$. The deviations $\varepsilon_{i j k}$ are from an $\mathrm{N}(0, \sigma)$ distributions. The means $\overline{\mathrm{U}}_{i j}$ represent the FIT part of the model and the RESIDUAL part is the deviation $\varepsilon_{i j k}$ of individual observation from their group means. To estimate a population mean $\bar{U}_{i j}$ in a twoway ANOVA design, sample mean of the observations is used as shown in equation. The sample variances for each SRS is calculated using pooled standard error $S_{p}$ as the estimator of standard deviation as shown in equation.

$$
\begin{gathered}
\bar{x}_{i j}=\frac{1}{n_{i j}} \sum_{k} x_{i j k} \\
s_{p}^{2}=\frac{\sum\left(n_{i j}-1\right) s_{i j}^{2}}{\sum\left(n_{i j}-1\right)}
\end{gathered}
$$

In investigating the effect of organic matter and time on undrained shear strength of the investigated soils, a null hypothesis was developed, stating that the variation in organic matter has no effect on strength and swell except due to changes in strength and swell over time. The test of significance was performed using ANOVA to assess the strength of the evidence against the null hypothesis. The significance of the effect of the investigated variables was tested using a representation of significance of the null hypothesis $(p$-value $=0.05)$ to ascertain the reliability and validation of the analysis [42].

\section{Results and Discussion}

The problems associated with swelling soils have generally occurred in clay soils predominated by expansive lattice type mineral such as montmorillonite [43]. However, clay soils can also be classified depending on their range of plasticity as low, medium or high swelling soils. This means that any factor capable of influencing the plasticity of clay can influence its swelling potential. The presence of organic matter in clay is one of such factors capable of affecting plasticity due to increase in liquid limit. Clay soils with low to high swelling capacities swell with increase in moisture content and this makes construction activities difficult due to density variation and subsequent strength variation. Undoubtedly, cement has been widely employed in the construction field for enhancement of plasticity, soil strength and compressibility [44-47]. However, with concerns about the environmental impact of cement-soil mixing becoming increasingly urgent, the application of by-product (ecofriendly) materials such as GGBS and CKD in soil mixing cannot be overemphasised. Therefore, this study has investigated the strength and swelling capacity of cemented medium swelling clay blended with GGBS and CKD.

\subsection{Undrained Shear Strength}

The shear strength is a fundamental property required in the analysis of construction projects over organic soils and it generally has limiting low value for such soils. Therefore, in the present study, the effect of varying organic matter on undrained shear strength of cemented clay blended with GGBS and CKD was studied. The results presented in Figure 1 shows a decrease in undrained shear strength for the different soil types in order of increasing organic matters $(0$ to $20 \%$ ) due to high affinity for water for organic materials. 
The undrained shear strength of the untreated soils decreases from $22.47 \mathrm{kPa}$ to $15.6 \mathrm{kPa}$ upon increase in organic matter from $0-20 \%$. The undrained shear strength of the investigated soils increases with time upon mixing with $20 \%$ CEM and 4\% CEM: $12 \%$ GGBS: $4 \%$ CKD due to hydration reaction as shown in Figure 2 (a-b). The strength increase can also be attributed to the gradual formation of cementitious compounds between CKD-GGBS due to higher cementing power of GGBS and a "pore-blocking" effect of hydraulic reactions of GGBS and CKD. Soil-GGBS mixtures could be used in highway embankments and this implies that deep mixing Soil-GGBS and with reduced amount of Cement can provide fill materials of comparable strength to most overconsolidated soils [48]. For clay soils with organic matters, the fibrous organic materials absorb water during mixing and loses it after hydration process and this creates barriers between soil particle-to-particle interactions. The fibrous barrier increases with increase in organic matter in the soil, reduces cementation effect and bonding between individual soils particles, and hence decrease in undrained shear strength. As a result, the undrained shear strength of the treated soil (soil 1) with $0 \%$ organic matter increase with time irrespective of additive type as shown in Figure 2 (a-b). Undrained shear strength increases from $632 \mathrm{kPa}$ to $804.9 \mathrm{kPa}$ and from $549.8 \mathrm{kPa}$ to $724.4 \mathrm{kPa}$ with reduction in organic matter upon addition of 20\% CEM and 4\% CEM: $12 \%$ GGBS: 4\% CKD after 56days. The results obtained show that the inclusion of GGBS and CKD reduced swell and increases undrained shear strength irrespective of the percentage of organic materials due to cementation effect. However, it is interesting to see that the inclusion of GGBS and $\mathrm{CKD}$ reduce effect of organic matter on undrained shear strength normalised arbitrary at 28 days compared to cement only treated soils due to pozzolanic reaction as shown in Figure $3(a-b)$. The results indicate that an increase in organic matter leads to suppression of pozzolanic reaction of the treated soils. It has been stated that stabilization effects on soil-cement admixture increased when fly ash additives were added to cement even at high organic matter content due to pozzolanic reaction [49]. The increase in strength upon addition of GGBS and CKD can be attributed to the presence of certain amount of $\mathrm{SiO}_{2}, \mathrm{Al}_{2} \mathrm{O}_{3}$ and $\mathrm{CaO}$, which enhanced the pozzolanic reaction between the soil- cement during curing time.

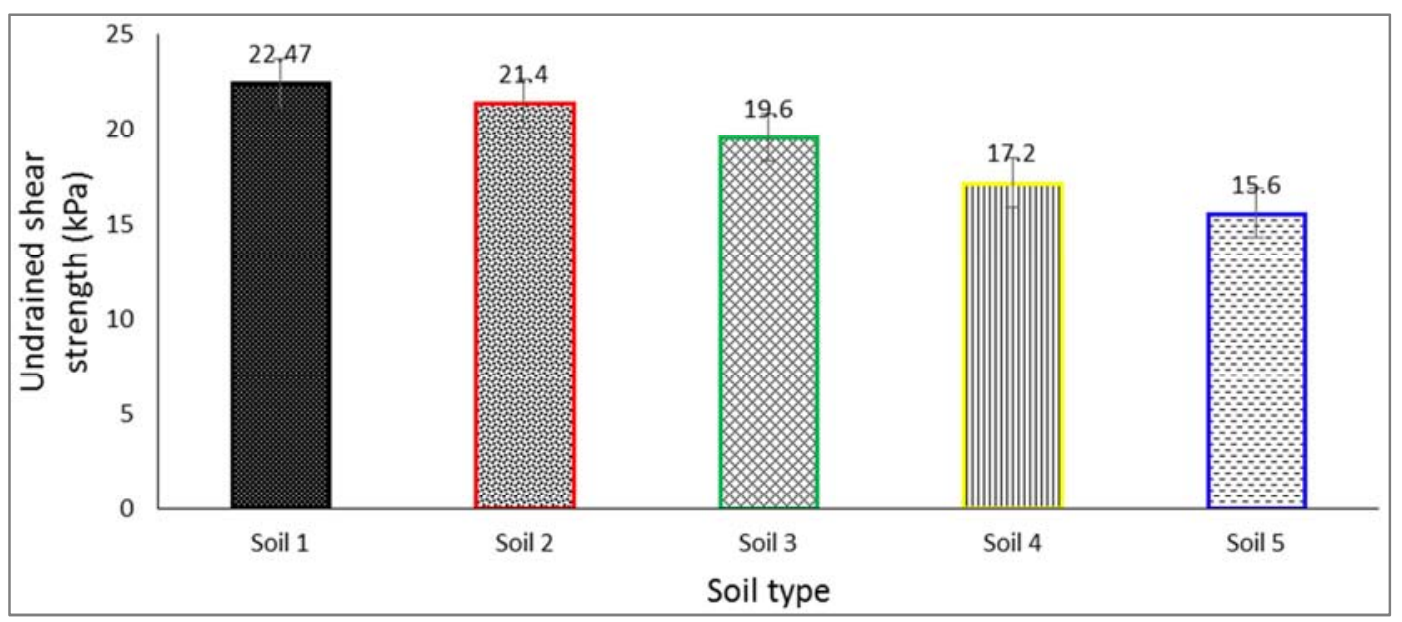

Figure 1. Effect of soil type on undrained shear strength.
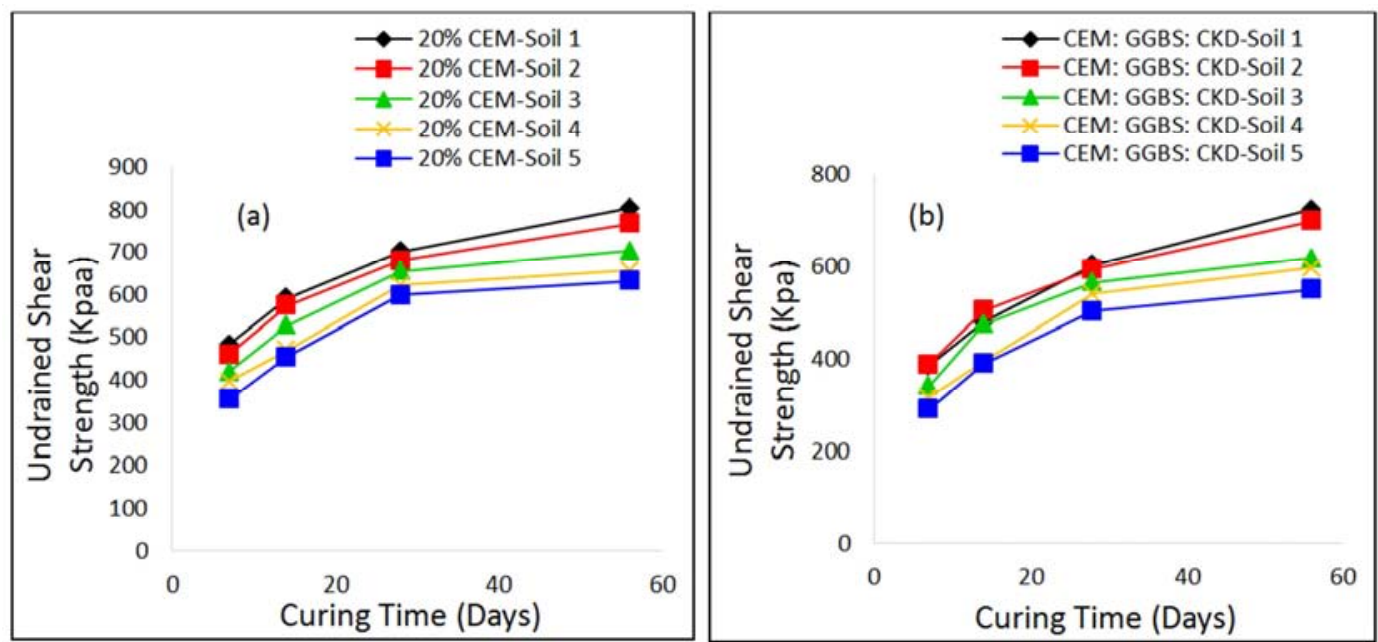

Figure 2. Variation of undrained shear strength of treated soils with time. 

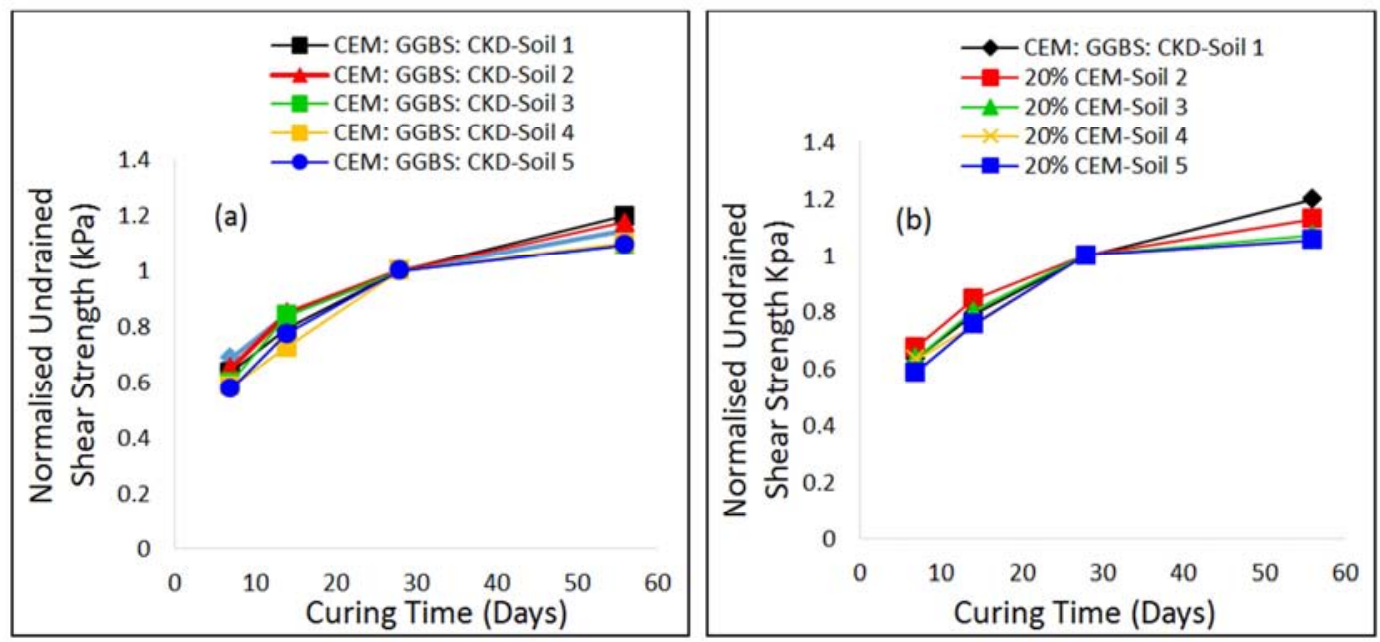

Figure 3. Variation of normalised undrained shear strength of treated soils with time.

It is true that the presence of organic matter in soils, reduces the effect of pozzolanic reactivity but the addition of GGBS increases pozzolanic reactivity [50]. The strength of an improved soil is an indication of the degree of reaction in the soil-binder-water mixture based on the rate of hardening of the improved mixture. Therefore, the type of binder used during deep mixing of soils with medium to high organic matter will be of great significance in determining the extent of improvement. For cement content between $5 \%$ to $20 \%$, soils of lower plasticity index exhibits higher strength enhancement compared to soils with slightly higher plasticity [30]. However, with the inclusion of GGBS/PFA and blended with less than 5\% Cement, soils of higher plasticity also increases in strength upon treatment due to $\mathrm{Ca}^{2+}$ exchange and pozzolanic reaction [51]. Soils with organic content (peat) possesses very low shear strength, low specific gravity and high-water content [52]. However, physical and mechanical properties of organic soils are enhanced upon stabilisation or treatment with byproduct cementitious materials as observed in the present study. This is due to reduced void ratio and filling of the space within organic soil particles by grouting or creatively prepared cementitious binder [53]. The strength gain can also be attributed to the neutralisation of humic acid within the soil with organic matters, which propagates the formation of more calcium silicate hydrate gel and increases the strength and densification of the stabilised organic soil [54].

\subsection{Swell}

The effect of organic matter on swell capacity of the different soil types was studied using 1-D oedometer compression test under $5 \mathrm{kpa}$ load and the displacement was recorded at different time intervals for 24 hours as shown in Figure 4 (a-c). The displacement-time curves show that the maximum displacement increases with increase in organic matter for both the treated and untreated soils. However, the soils treated with CEM/GGBS/CKD show higher efficiency in reducing displacement compared to soils treated with Cement only. The swell capacity of the treated and untreated soils defined in terms of percentage swell was derived using the load displacement-curves at maximum displacement. The results presented in Figure $5(\mathrm{a}-\mathrm{b})$ to Figure 6, show that swell increases from $1.17 \%$ to $3.83 \%$ for the same range of $0-20 \%$ organic matter and for the samples treated with $4 \%$ cement and inclusion of $12 \%$ GGBS and $4 \%$ CKD, the treated soils showed better performance in terms of swell potential due to reduction in plasticity compared to the plasticity of soils treated with $20 \%$ cement.
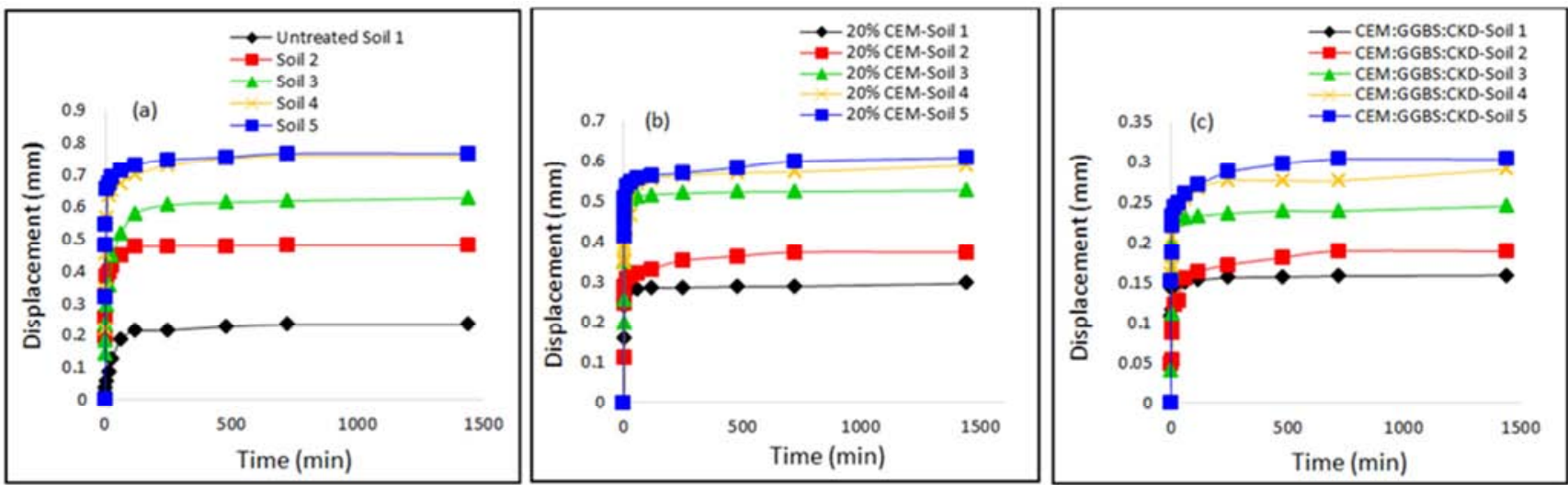

Figure 4. Displacement of treated and untreated soils with time. 

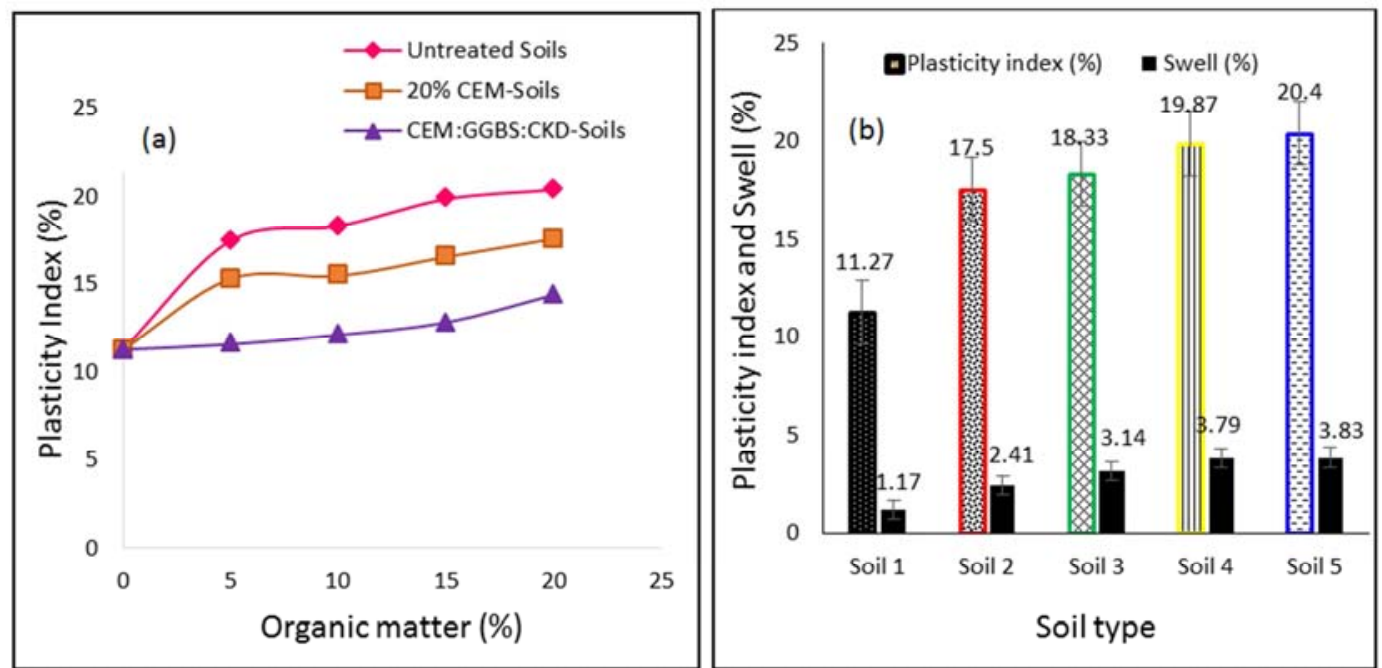

Figure 5. Effect of organic matter on plasticity and swell.

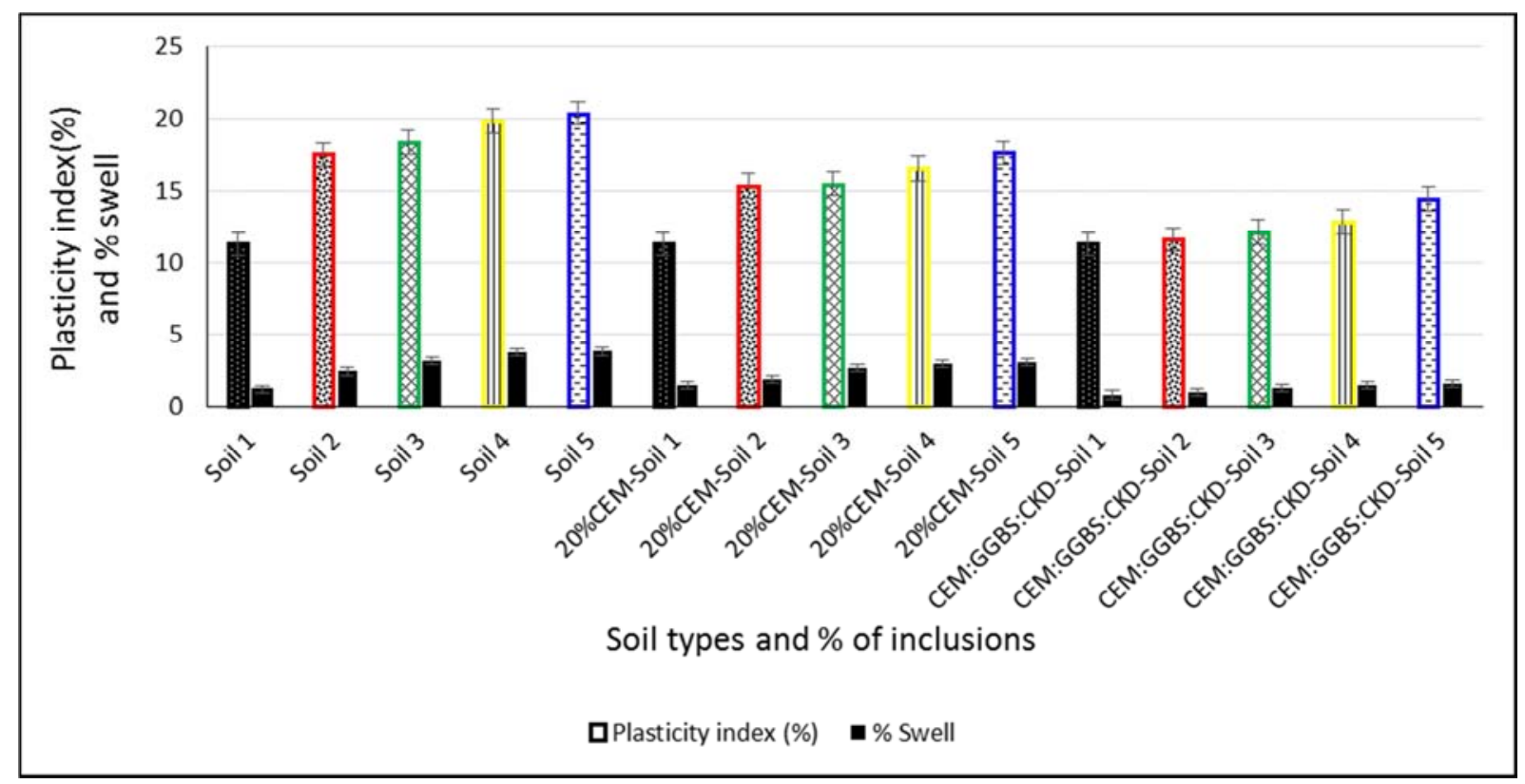

Figure 6. Effect of cementation and GGBS/CKD inclusion on plasticity and swell.

The presence of organic matters in the soils increases liquid and plastic limits and hence, plasticity index. It has been stated in previous section that swelling capacity increases with plasticity index and this is evidenced in this study. The results plotted in Figure 5 (a-b) shows that increase in organic matter causes a corresponding increase in plasticity index and hence, swell. This implies that the presence of organic matters in clay with medium swell capacity increases swell due to increased moisture content absorbed by the fibrous materials. The plasticity index of Cement treated soils was found to be greater than that of the CEM/GGBS/CKD treated soils at $20 \%$ additive content as shown in Figure 5 (a). This can be attributed to the higher plasticity index of the untreated soils with varying organic matters. Figure 6 shows that greater reduction in plasticity index for soils treated with CEM/GGBS/CKD resulted to corresponding reduction in swell compared to Cement treated soils at $20 \%$ additive content. This explains the suitability of cementitious by-product materials such as GGBS and CKD in treatment of soils with varying organic matters due to pozzolanic activity of GGBS and water absorptive quality of CKD.

\subsection{Statistical Validation of Investigated Factors}

Statistical analysis was performed using ANOVA to investigate the contributions of the different levels of the independent factors (organic matter, curing time and additive type) on undrained shear strength and swell. The significance of the effect of organic matter on undrained shear strength and swell capacity of a medium swell clay was analysed. It was assumed that the independent factors have no effect on the undrained strength and swell (null hypothesis). In order to test the significance of the null hypothesis of the F- test in ANOVA the P-values (representation of significance of the 
null hypothesis) was compared to some alpha level (0.05). The influence of the independent factors in predicting the response variable is usually considered significant when Fstatistics is greater than the F-critical value, and the corresponding p-value is less than $5 \%$.

Effect of Organic Matter

i. Undrained Shear Strength

The effect of the varying organic matters on undrained shear strength (response variable) was validated via analysis of variance in a two-way design. The ANOVA was defined in terms of two independent factors (organic matter and time). The significance of each factor was examined, and the results are presented in Table 5 to Table 7 . The result presented in Table 6 shows that F-statistics value is greater than the Fcritical with a p-value less than 0.05 . This implies that it can be claimed with $95 \%$ confidence that the effect of organic matter and curing time contributed to the observed changes in undrained shear strength as expected. In other words, the investigated independent factors are significant in the observed changes in undrained shear strength with Fstatistics greater than F-critical and p-value less than 5\% as shown in Table 6. The results presented in Table 7 and Table 8 also show the significance of the effect of organic matter and curing and the reasons to reject the null hypothesis. Table 8 shows that the F-statistics is greater than F-critical and pvalue less than $5 \%$. This shows that the percentage of organic matter and curing time are significant in the observed changes for undrained shear strength and this is consistent with previous results presented in section 3.1. This implies that the presence of organic matters has the tendency of affecting the performance of soils stabilised with cement and blend of GGBS and CKD.

Table 5. Variance analysis of undrained shear strength of $20 \%$ CEM treated soils.

\begin{tabular}{|c|c|c|c|c|}
\hline SUMMARY & Sample Count & Sum & Average & Variance \\
\hline 20\% CEM-Soil 1 & 4 & 2580.4 & 645.1 & 19374.7 \\
\hline 20\% CEM-Soil 2 & 4 & 2484.5 & 621.1 & 17622.2 \\
\hline 20\% CEM-Soil 3 & 4 & 2306.5 & 576.6 & 16272.1 \\
\hline 20\% CEM-Soil 4 & 4 & 2144 & 536.0 & 15264.9 \\
\hline 20\% CEM-Soil 5 & 4 & 2038.9 & 509.7 & 16671.5 \\
\hline \multicolumn{5}{|l|}{ Time (days) } \\
\hline 7 days & 5 & 2115.8 & 423.2 & 2605.8 \\
\hline 14 days & 5 & 2616.1 & 523.2 & 3739.5 \\
\hline 28 days & 5 & 3258.5 & 651.7 & 1769.1 \\
\hline 56 day & 5 & 3564.0 & 712.8 & 5352.1 \\
\hline
\end{tabular}

Table 6. ANOVA-Two factor without replication for 20\% CEM treated soils.

\begin{tabular}{llllll}
\hline Source of Variation & Sum of squares & Degree of freedom & Mean square & F & Fcrit \\
\hline Organic matter (\%) & 51159.2 & 4 & 12789.8 & 56.7 & 3.3 \\
Curing time (days) & 252910.2 & 3 & 84303.4 & 373.8 & $3.1 \mathrm{E}-07$ \\
Error & 2706.4 & 12 & 225.5 & & \\
Total & 306775.8 & 19 & & & \\
\hline
\end{tabular}

Table 7. Variance analysis on undrained shear strength of CEM: GGBS: CKD treated soils.

\begin{tabular}{|c|c|c|c|c|}
\hline SUMMARY & Sample Count & Sum & Average & Variance \\
\hline CEM: GGBS: CKD-Soil 1 & 4 & 2192.9 & 548.2 & 21753.0 \\
\hline CEM: GGBS: CKD-Soil 2 & 4 & 2186.9 & 546.7 & 17518.6 \\
\hline CEM: GGBS: CKD-Soil 3 & 4 & 2000.4 & 500.1 & 14808.5 \\
\hline CEM: GGBS: CKD-Soil 4 & 4 & 1849.7 & 462.4 & 16705.9 \\
\hline CEM: GGBS: CKD-Soil 5 & 4 & 1732.7 & 433.2 & 13548.3 \\
\hline \multicolumn{5}{|l|}{ Time (days) } \\
\hline 7 days & 5 & 1722.4 & 344.5 & 1810.1 \\
\hline 28 days & 5 & 2808.7 & 561.7 & 1694.4 \\
\hline 56 days & 5 & 3188.8 & 637.8 & 5260.1 \\
\hline
\end{tabular}

Table 8. ANOVA-Two factor without replication for CEM: GGBS: CKD treated soils.

\begin{tabular}{llllll}
\hline Source of Variation & Sum of squares & Degree of freedom & Mean square & F & P-value \\
\hline Organic matter (\%) & 41465.8 & 4 & 10366.4 & 25.3 & $9.1 \mathrm{E}-06$ \\
Curing time (days) & 248082.5 & 3 & 82694.2 & 201.7 \\
Error & 4920.5 & 12 & 410.1 & $3.6 \mathrm{E}-10$ \\
Total & 294468.8 & 19 & & \\
\hline
\end{tabular}


ii. Swell

In the case of swell, samples were tested only at 7days and therefore, the analysis of variance in a two-way design was defined in terms of organic matter and type of additives. The significance of each factor on the swelling capacity of the investigated soils was examined and validated, for which the results are presented in Table 9 and 10 respectively. The result presented in Table 10 shows that the F-statistics is greater than the F-critical and a p-value less than 0.05 . Therefore, it can be claimed with $95 \%$ confidence that the effect of organic matter and additive type contributed to the observed changes in swelling capacity of the investigated soils. This is consistent with the results presented in section 3.2 and very strong evidence to reject the null hypothesis.

Table 9. Variance analysis on swell of CEM and CEM: GGBS: CKD treated soils.

\begin{tabular}{lllll}
\hline SUMMARY & Count & Sum & Average \\
\hline Soil 1 & 3 & 3.45 & 1.15 & Variance \\
Soil 2 & 3 & 5.23 & 0.1159 \\
Soil 3 & 3 & 7.005 & 2.335 \\
Soil 4 & 3 & 8.19 & 2.73 & 0.5449 \\
Soil 5 & 3 & 8.39 & 2.7966 & 0.9795 \\
Untreated soils & 5 & 14.34 & 1.868 & 1.3962 \\
CEM treated soil & 5 & 11.969 & 2.3938 & 1.3784 \\
CEM: GGBS: CKD treated soils & 5 & 5.956 & 0.4719 \\
\hline
\end{tabular}

Table 10. ANOVA-Two factor without replication for CEM and CEM: GGBS: CKD treated soils for swell.

\begin{tabular}{|c|c|c|c|c|c|c|}
\hline Source of Variation & Sum of Squares & Degree of freedom & Mean Square & $\mathbf{F}$ & P-value & F crit \\
\hline Organic matter $(\%)$ & 5.862527 & 4 & 1.4656 & 8.6 & 0.0053 & 3.8 \\
\hline Type of Additive & 7.471284 & 2 & 3.7356 & 21.9 & 0.0006 & 4.5 \\
\hline Error & 1.358771 & 8 & 0.1699 & & & \\
\hline Total & 14.69258 & 14 & & & & \\
\hline
\end{tabular}

\section{Conclusions}

The undrained shear strength and swell potential are concerns during construction for supporting construction equipment as well at the end of construction in supporting the structure. Organic soils present a distinct behaviour than inorganic soils due to fibrous organic matter. The effect of this fibrous matters on strength and swell has been investigated for Cement and CEM/GGBS/CKD treated soils. Following the analysis and results of this study, the following conclusions have been drawn:

The presence of organic matters in clay reduces undrained shear strength and increases swell potential of the untreated soil due to the presence of fibrous organic matters and high moisture ingress but the treatment with CEM, GGBS and CKD reduces swell potential.

The undrained shear strength of soil with $0 \%$ organic matter treated using 20\% CEM and 4\% CEM with inclusion of $8 \%$ GGBS and $4 \%$ CKD is greater in all cases compared to that of soils with varying organic matter.

Soils treated using 4\% CEM and inclusion of $8 \%$ GGBS and $4 \%$ CKD produces better performance in terms of reduction in plasticity index of the treated soils and hence swell reduction.

The use of CEM and inclusion of GGBS and CKD can provide engineering benefits to control swelling of organic soils and enhanced undrained shear strength, when used in moderate proportions especially in the case of cement.

Results of the statistical studies show that the presence of organic matter influences the extent of performance of cement, GGBS and CKD treated soils.

\section{References}

[1] Onitsuka K, Modmoltin C, Kouno M, Negami T. Effect of organic matter on lime and cement stabilized ariake clays. Journal of Geotechnical Engineering 2003: 1-13.

[2] Bennett RH, Lehman L, Hulbert MH, Harvey GR, Bush SA, Forde EB, et al. Interrelationships of organic carbon and submarine sediment geotechnical properties. Marine Geotechnology 1985; 6: 61-98. doi: $10.1080 / 10641198509388180$.

[3] Booth JS, Dahl AG. A note on the relationships between organic matter and some geotechnical properties of a marine sediment. Marine Geotechnology 1986; 6: 281-97. doi: 10.1080/10641198609388191.

[4] Tremblay H, Duchesne J, Locat J, Leroueil S. Influence of the nature of organic compounds on fine soil stabilization with cement. Canadian Geotechnical Journal 2002; 546: 535-46. doi: 10.1139/T02-002.

[5] Morrill LG, Mahilum BC, Mohiuddin SH. Organic compounds in soils: Sorption, degradation and persistence. Ann Arbor Science Publishers; 1982.

[6] Zurairahetty N, Yunus M, Wanatowski D, Hassan NA, Marto A. Shear Strength and Compressibility Behaviour of Limetreated Organic Clay. KSCE Journal of Civil Engineering 2015; 00: 1-7. doi: 10.1007/s12205-015-0438-5.

[7] Clare KE, Sherwood PT. The effect of organic matter on the setting of soil-cement mixtures. Journal of Applied Chemistry 2007; 4: 625-30. doi: 10.1002/jctb. 5010041107. 
[8] Yunus NZM, Wanatowski D, Stace LR. Effect of Humic Acid on Physical and Engineering Properties of Lime-Treated Organic Clay 2011; 5: 724-9.

[9] Banaszkiewicz K, Marcinkowski T. Use of cement-fly ashbased stabilization techniques for the treatment of waste containing aromatic contaminants 2017; 00009. doi: $10.1051 /$ e3sconf $/ 20172200009$.

[10] Oliveira P, Correia A, Garcia MR. Effect of Organic Matter Content and Curing Conditions on the Creep Behavior of an Artificially Stabilized Soil. Journal of Materials in Civil Engineering 2016; 25: 864-70. doi: 10.1061/(ASCE) MT. 1943-5533.

[11] Sing WL, Hashim R, Ali FH. Unconfined Compressive Strength of Cemented Peat 2009; 3: 3850-6.

[12] Harris P, Harvey O, Puppala AJ, Sebesta S, Rao S, Saride S. Mitigating the effect of 2009; 7.

[13] Tastan EO, Edil TB, Benson CH, Aydilek AH. Stabilization of Organic Soils with Fly Ash. Journal of Geotechnical and Geoenvironmental Engineering 2011; 137: 819-33. doi: 10.1061/(ASCE) GT. 1943-5606.0000502.

[14] Nath BD, Molla KA, Sarkar G. Study on Strength Behavior of Organic Soil Stabilized with Fly Ash. International Scholarly Research Notices 2017; 2017.

[15] Åhnberg H, Bengtsson P-E, Holm G. Effect of initial loading on the strength of stabilised peat. Proceedings of the Institution of Civil Engineers - Ground Improvement 2001; 5: 35-40. doi: 10.1680/grim. 2001.5.1.35.

[16] Kang G, Tsuchida T, Kim Y, Baek W. Influence of Humic Acid on the Strength Behavior of Cement-Treated Clay during Various Curing Stages 2017; 29: 1-18. doi: 10.1061/(ASCE) MT. 1943-5533.0001919.

[17] Young JF. A review of the mechanisms of set-retardation in portland cement pastes containing organic admixtures. Cement and Concrete Research 1972; 2: 415-33. doi: 10.1016/0008-8846 (72) 90057-9.

[18] Parkkinen E. Utilization of industrial by-products to strengthen soft clayey and organic soils Utilisation des sousproduits de I industrie pour renforcer des sols tendres organiques et argileux. Proceedings of the 14th International Conference on Soil Mechanics and Foundation Engineering (ICSMFE), Hamburg, Germany: 1997, p. 1701-4.

[19] Montgomery DM, Soliars CJ, Perry R, Tariingt SE, Barnes P, Henderson E. Treatment of Organic-Contaminated Industrial Wastes Using Cement-Based Stabilization/Solidification- I. Microstructural Analysis of Cement-Organic Interactions. Waste Management \& Research 1991; 9: 103-11.

[20] Kamon M, Tomohisa S, Sawa K. On Stabilization of Hedoro by Using Cement Group Hardening Materials. Jour- Nal of the Society of Materials Science 1989; 432: 1092-7. doi: 10.2472/jsms. 38.1092.

[21] Ahnberg H, Ljungkrantz C, Johansson S-E, Retelitus A, Holmqvist L, Holm G. Cement och kalk för djupstabilisering av jord En kemisk - fysikalisk studie av stabiliseringseffekter. 1995

[22] Huat BBK, Maail S, Mohamed T. Effect of cement admixtures on the engineering properties of tropical peat soils. American Journal of Applied Sciences 2005; 2: 1113-20. doi: 10.3844/ajassp. 2005.1113.1120.
[23] Chen H, Wang Q. The behaviour of organic matter in the process of soft soil stabilization using cement. Bulletin of Engineering Geology and the Environment 2006; 65: 445-8. doi: 10.1007/s10064-005-0030-1.

[24] Tindall J, Kunkel J. Unsaturated Zone Hydrology for Scientists and Engineers. Prentice Hall, Engelwood Cliffs, New Jersey; 1999.

[25] Phanikumar BR, Sharma RS. Volume change behavior of fly ash-stabilized clays. Journal of Materials in Civil Engineering 2007; 19: 67-75.

[26] Consoli NC, Da Rocha CG, Silvani C. Devising dosages for soil-fly ash-lime blends based on tensile strength controlling equations. Construction and Building Materials 2014; 55: 238-45. doi: 10.1016/j.conbuildmat. 2014.01 .044

[27] Seco A, Ramírez F, Miqueleiz L, García B. Stabilization of expansive soils for use in construction. Applied Clay Science 2011; 51: 348-52.

[28] Khoury NN, Zaman MM. Environmental effects on durability of aggregates stabilized with cementitious materials. Journal of Materials in Civil Engineering 2007; 19: 41-8.

[29] Peethamparan S, Olek J, Lovell J. Influence of chemical and physical characteristics of cement kiln dusts (CKDs) on their hydration behavior and potential suitability for soil stabilization. Cement and Concrete Research 2008; 38: 80315. doi: 10.1016/j.cemconres. 2008.01.011.

[30] Abbey SJ, Ngambi S, Coakley E. Effect of cement and byproduct material inclusion on plasticity of deep mixing improved soils. International Journal of Civil Engineering and Technology 2016; 7: 265-74.

[31] Abbey SJ, Olubanwo AO. Strength and hydraulic conductivity of cement and by-product cementitious materials improved soil. International Journal of Applied Engineering Research 2018; 13: 8684-94.

[32] Abbey SJ, Ng'ambi S, Ganjian E. Development of strength models for prediction of unconfined compressive strength of cement/by-product material improved soils. Geotechnical Testing Journal 2017; 40: 928-35. doi: 10.1520/GTJ20160138.

[33] Eyo EU, Ngambi S, Abbey SJ. Investigative modelling of behaviour of expansive soils improved using soil mixing technique. International Journal of Applied Engineering Research 2017; 12: 3828-36.

[34] Obuzor GN, Kinuthia JM, Robinson RB. Enhancing the durability of flooded low-capacity soils by utilizing limeactivated ground granulated blastfurnace slag (GGBS). Engineering Geology 2011; 123: 179-86. doi: 10.1016/j.enggeo. 2011.07.009.

[35] Celik E, Nalbantoglu Z. Effects of ground granulated blastfurnace slag (GGBS) on the swelling properties of limestabilized sulfate-bearing soils. Engineering Geology 2013; 163: $20-5$.

[36] Wang D, Zentar R, Abriak NE. Durability and Swelling of Solidified/Stabilized Dredged Marine Soils with Class-F Fly Ash, Cement, and Lime. Journal of Materials in Civil Engineering 2018; 30: 04018013. doi: 10.1061/(ASCE) MT. 1943-5533.0002187. 
[37] Erdal Cokca. Use of class C fly ashes for the stabilization of an expansive soil. Journal of Geotechnical and Geoenvironmental Engineering 2001; 127 (7): 568-73. doi: 10.1017/CBO9781107415324.004.

[38] EuroSoilStab. Design Guide Soft Soil Stabilisation. Ct970351 1997: 95.

[39] Ganjian E, Jalull G, Sadeghi-Pouya H. Using waste materials and by-products to produce concrete paving blocks. Construction and Building Materials 2015; 77: 270-5. doi: 10.1016/j.conbuildmat. 2014.12.048.

[40] Jalull G, Ganjian E, Sadeghi-Pouya H. Using ground granulated blastfurnace slag and mineral wastes to reduce cement in paving block. Proceedings of Institution of Civil Engineers: Construction Materials 2014; 167. doi: 10.1680/coma. 13.00011.

[41] Puppala AJ, Manosuthikij T, Chittoori B. Swell and shrinkage characterizations of unsaturated expansive clays from Texas. Engineering Geology 2013; 164: 187-94.

[42] Rawlings JO, Pantula SG, Dickey DA. Applied Regression Analysis: A Research Tool, Second Edition. vol. 18. 1998. doi: $10.1007 / \mathrm{b} 98890$.

[43] Goodarzi AR, Akbari HR, Salimi M. Enhanced stabilization of highly expansive clays by mixing cement and silica fume. Applied Clay Science 2016; 132-133: 675-84. doi: 10.1016/j. clay. 2016.08.023.

[44] Abbey SJ, Ngambi S, Ngekpe BE. Understanding the performance of deep mixed column improved soils - A review. International Journal of Civil Engineering and Technology 2015; 6: 97-117.

[45] Farouk A, Shahien MM. Ground improvement using soilcement columns: Experimental investigation. Alexandria Engineering Journal 2013; 52: 733-40. doi: 10.1016/j.aej. 2013.08.009.
[46] Gaafer M, Bassioni H, Mostafa T. Soil Improvement Techniques. International Journal of Scientific \& Engineering Research 2015; 6: 217-22.

[47] Wu Z, Deng Y, Liu S, Liu Q, Chen Y, Zha F. Strength and micro-structure evolution of compacted soils modified by admixtures of cement and metakaolin. Applied Clay Science 2016; 127-128: 44-51. doi: 10.1016/j.clay. 2016.03.040.

[48] Shridevi G, Sreerama R. Efficacy of GGBS Stabilized Soil Cushions With and Without Lime in Pavements. International Journal of Emerging Technologies in Computational and Applied Sciences (IJETCAS) 2014: 141-7.

[49] Shao L., Liu S, Du Y, Jing F., Fang L., ' Experimental Study on the Stabilization of Organic Clay with Fly Ash and Cement Mixed Method", Geocongress 2008: Characterization, Monitoring, and, Modeling Of Geosystems.

[50] Kitazume M, Terashi M. The deep mixing method. 1st editio. CRC Press; 2013.

[51] Al-Swaidani A, Hammoud I, Meziab A. Effect of adding natural pozzolana on geotechnical properties of limestabilized clayey soil. Journal of Rock Mechanics and Geotechnical Engineering 2016; 8: 714-25. doi: 10.1016/j.jrmge. 2016. 04. 002.

[52] Jin, F., Wang, F. and Al-Tabbaa, A. (2016). Three-year performance of in-situ solidified/stabilised soil using novel MgO-bearing binders. Chemosphere, 144, pp. 681-688.

[53] Abdel-Salam, A. (2018). Stabilization of peat soil using locally admixture. HBRC Journal, 14 (3), pp. 294-299.

[54] Md Yusof, Z., Mohd Harris, S. and Mohamed, K. (2015). Compressive Strength Improvement of Stabilized Peat Soil by Pond Ash - Hydrated Lime Admixture. Applied Mechanics and Materials, 747, pp. 242-245. 